\title{
Breve panorama acerca da crítica regiliosa nas obras La Celestina e Lazarillo de TORMES
}

\author{
Ana Laura Rala
}

\begin{abstract}
Resumo
A partir do século XV, na Espanha, as influências proporcionadas pelo frutífero movimento humanista, surgido na Itália, marcaram um momento de grande transformação da estática sociedade medieval à efervescente atividade renascentista, a qual deu origem a uma vasta gama de mudanças de concepções, como o retorno aos valores clássicos, a defesa pelo racionalismo e o abandono à visão teocêntrica, perspectivas anteriormente impensáveis e cujas consequências afetaram a todos os modos de ver e compreender o mundo. Nesse rico contexto de alterações dos paradigmas estabelecidos, destacam-se as relações entre o humano e o divino, cujo impulso trazido pelo Renascimento permitiu lançar um novo olhar sobre um dos grandes temas da Idade Média: a questão religiosa. Nesse sentido, considerando, portanto, o novo pensamento da sociedade espanhola refletido também em sua literatura, o presente trabalho tem por objetivo traçar um breve panorama a respeito da crítica religiosa presente em duas importantes obras dos séculos XV e XVI: La Celestina, de Rojas e Lazarillo de Tormes, de autoria anônima, enfatizando, especialmente, este último. Assim, pretende-se evidenciar esse momento de transição e observá-lo em autores que, sem exageros, podem ser considerados escritores que atuaram à frente de seu tempo ao possibilitarem, através da arte, o questionamento da ordem vigente.
\end{abstract}

Palavras-chave: literatura espanhola; transição; renascimento.

\section{Resumen}

A partir del siglo XV, en España, las influencias proporcionadas por el fructífero movimiento humanista italiano marcaron un momento de gran transformación de la estática sociedad medieval a la efervescente actividad renacentista, la cual originó una amplia gama de cambios de concepciones, como el retorno a los valores clásicos, la defensa por la racionalidad y el abandono a la visión teocéntrica, perspectivas anteriormente impensables cuyas consecuencias afectaron a todos los modos de ver y de comprender el mundo. En este contexto de significativas modificaciones de los paradigmas establecidos, se destacan sobre todo las relaciones entre lo humano y lo divino, cuyo impulso del Renacimiento permitió lanzar una nueva mirada acerca de una de las grandes preocupaciones de la Edad Media: lo religioso. En ese sentido, considerando, por lo tanto, el nuevo pensamiento español reflejado también en su literatura, el presente texto tiene por objetivo trazar un breve panorama sobre la crítica religiosa en dos importantes obras de los siglos XV y XVI: La Celestina, de 
Rojas y Lazarillo de Tormes, de autoría anónima, enfatizando, especialmente, este último. Así, se pretende evidenciar ese período de transición y observarlo en autores que, sin exageraciones, pueden ser considerados escritores que actuaran al frente de su tiempo al posibilitaren, a través del arte, el cuestionamiento del orden vigente.

Palabras clave: literatura española; transición; renacimiento.

\title{
INTRODUÇÃO
}

As influências do humanismo italiano, a partir do século XV, na Espanha, marcaram um período de transição "de la inerte sociedad medieval a la plural renacentista". Neste contexto de mudança de concepções está situada a Tragicomedia de Calisto y Melibea, que posteriormente, e com algumas modificações, passaria a se chamar La Celestina, de Fernando Rojas.Segundo Esther Borrego, a obra

\begin{abstract}
Supone una síntesis de todas las corrientes culturales medievales y de las nuevas tendencias renacentistas y, para los que consideran que es uno de los pilares de la novela moderna-junto con El Quijote y el Lazarillo de Tormes-, es un hito en el modo de abordar la novelística, aunque naciera como obra dramática y así fuera entendida en su tiempo (BORREGO, 2014).
\end{abstract}

Deste modo, se La Celestina pode ser considerada um marco na transformação do pensamento espanhol e, consequentemente, de sua literatura, é importante ressaltar a consciência de crise diante do contexto da Idade Média já presente na obra, o que influenciará depois escritores do século XVI. Assim, conforme afirma Maravall (1964, p.13), La Celestina traz consigo a inovação em seu fundo filosófico e moralizante acerca das causas humanas. Tal aspecto é comum às obras posteriores que virão já no contexto do chamado "siglo de oro", momento de grande efervescência na produção artística e literária.

Nesse sentido, o presente trabalho tem por objetivo traçar um breve panorama a respeito da crítica religiosa presente em três importantes obras dos séculos XV e XVI: La Celestina, de Rojas; Diálogo de Mercúrio y Carón, de Alfonso de Valdés e Lazarillo de Tormes, de autoria anônima² ${ }^{2}$ enfatizando, sobretudo, este último.

\section{La Celestina}

Segundo Jiménez (2015, p.73), o período de reinado dos chamados "Reis Católicos" (1474-1516), na Espanha, foi fundamental para possibilitar o surgimento de novas formas renascentistas que vão consolidando-se ao largo do século XV e alcançam seu auge no reinado de Carlos I. Assim, inaugura-se uma nova concepção de vida, em oposição à medieval, na qual o homem é o centro do mundo; visão que estará presente em La Celestina. Ademais, este período foi marcado por grandes acontecimentos históricos, que influenciaram a vida social e política, os quais interessam para esta análise: o fim da Reconquista; culminação do antissemitismo; elevação da intolerância religiosa; a Inquisição; além de uma concepção 
antropocêntrica, que idealiza a realidade e acarreta na mudança de perspectiva do cristão em relação à morte e às coisas terrenas.

Conforme salienta Martín (1999), o âmbito religioso em La Celestina ainda é ponto de grande debate na literatura, uma vez que se discute se há crítica religiosa e, que se houver, é uma crítica da perspectiva judia ou cristã. Para a autora, entretanto,

en La Celestina todo se derrumba y destruye: la sociedad y la cultura en la que el texto está asentado; el mundo en el que vive el autor y, por supuesto, también la religión. Por ello en la obra no hay sentimiento religioso alguno (ni cristiano ni judaico). Todo se convierte en una sátira destructiva y letal (MARTÍN, 1999, p.49).

Assim, a autora defende que, a pesar da origem judia de Fernando de Rojas, há maior presença de elementos cristãos na obra, dada a condição da Inquisição; porém a sua sátira alcança tudo. A fim de demonstrar, ainda que brevemente, como se dá esta sátira ao religioso na obra, destacaremos a seguir alguns elementos que nos permitem visualizar isto.

Um dos momentos em que fica clara a sátira religiosa é quando Calisto, perdidamente apaixonado por Melibea, se declara "melibeo", como se ela fosse seu Deus e sua religião, algo impensável em um contexto medieval de fé cristã.

CALISTO - En esto veo, Melibea, la grandeza de Dios.

SEMPRONIO - ¿Tú no eres cristiano?

CALISTO - ¿Yo? Melibeo soy y a Melibea adoro y en Melibea creo y a Melibea amo (ROJAS, p.16).

Em outro momento, Sempronio, servo de Calisto, coloca as religiões em acordo, no que diz respeito às mulheres: "Gentiles, judíos, cristianos y moros, todos en esta concordia están” (p.18). Outro aspecto que chama atenção quanto à sátira religiosa é a ausência da ideia do suicídio como pecado, dado o ato desesperado de Melibea e o desejo de seus pais ao saberem de sua morte. Ainda há constantes referências às passagens bíblicas, como quando Pármeno lembra-se do conselho que sua mãe um dia lhe deu: "La paz no se debe negar, que bienaventuradossonlos pacíficos, que fijos de Diosseránllamados” (p.36).

Dessa forma, conforme Martín (1999), o que há em La Celestina é "religión en su forma desviada", neste sentido, as referências bíblicas são utilizadas de modo perverso, as orações são interessadas, o divino é clamado somente pelo interesse das personagens às coisas terrenas, como o amor, o dinheiro e ascensão social. A própria Celestina, sendo feiticeira, interfere no destino e o altera, fato que numa visão cristã seria impossível dado que este é predestinado e escrito por Deus. Até a ironia de seu nome reforça a sátira: uma bruxa e prostituta com um nome que remete ao celestial. Nestas observações podemos ver a destruição de valores judaico-cristãos.

Segundo Ramos (2002), há ainda a presença de uma "cultura religiosa", presente na 
linguagem das personagens, como em expressões coloquiais, ou em hábitos próprios da época. A autora ressalta também que religiosidade refere-se "uma ética e a uma filosofia moral baseadas em princípios religiosos" que na obra aparecem desmontados.

Rojas, com uma perspectiva crítica diante da sociedade na qual estava inserido, a observa e descreve de forma sarcástica. Américo Castro afirma ainda que "la finalidad de esta tragicomedia no fue moralizar ni criticar primordialmente el orden social o religioso. Lo que esto haya es reflejo secundario de otros propósitos más hondos: la perversión y el trastorno de las jerarquías de valoración vigentes, de los ideales poéticos y caballerescos" (In CARDIEL SANZ, 1981, p. 157-158 apud MARTÍN, 1999).

\section{LAZARILlo DE TORMES}

Publicada anonimamente devido ao conteúdo herético, a história presente em Lazarillo de Tormes se passa durante a primeira metade do século XVI. Assim, a obra retrata de forma crítica a sociedade da época e do sistema social e clerical vigentes, que condicionam e determinam a vida das pessoas.

Segundo Shekhar, Lázaro - nome que provavelmente remete ao pobre personagem bíblico - é um pícaro, isto é, o anti-herói típico da literatura picaresca.

El Lazarillo ejemplifica un proceso educativo al revés. Explica el aprendizaje del pícaro en su lucha por la vida, en su camino de vileza y deshonor. El pícaro es producto de una sociedad invertida, donde todo está trastocado y los religiosos no viven según manda la Biblia, ni los hidalgos con nobleza. Si todo está al revés, también lo estará la mentalidad del héroe (SHEKHAR, S/D, pp.6-7).

Nesse sentido, o protagonista, marginalizado desde seu nascimento, busca sobreviver como pode em meio à sua miserável vida junto aos seus amos, em sua maioria, eclesiásticos. Lázaro, de modo autobiográfico, conta sua trajetória em sete tratados.

Vale ressaltar que Navarro (2008) defende a autoria de Lazarillo de Tormes como obra de Alfonso de Valdés, devido, sobretudo, à semelhante crítica anticlerical de ideologia erasmista, presente em Diálogo de Mercurio y Carón. Além disso, a autora chama a atenção para o anonimato dos amos de Lázaro: nenhum recebe um nome e, deste modo, a crítica ganha uma dimensão "universal".

Dos sete amos que Lázaro serve, quatro deles pertencem ao clero e não agem conforme o cristianismo, isto é, não demonstram caridade, além de serem viciosos. São eles: "el clérigo", "el fraile de la Merced", "el buldero" y "el arcipreste". Segundo Kadyan (2014), mediante estes personagens, o autor pode criticar o clero e a Igreja enquanto instituição.

No Segundo Tratado, Lázaro se coloca a serviço de um clérigo avarento e muito egoísta, que coloca o inocente pícaro em um estado de fome desumano. Um exemplo disso é 
quando o clérigo, cruelmente, oferece ao Lazarillo pedaços de pão que ele acredita serem mordidos por ratos:

\footnotetext{
Rayó con un cuchillo todo lo que pensó ser ratonil diciendo:

- Cómete eso, que el ratón cosa limpia es.
}

Nesse sentido, é notável que o clérigo não se importa com a integridade e saúde de Lázaro, somente com ele mesmo - um egoísmo que não condiz com o cristianismo. Em outros momentos do tratado, é possível observar várias atitudes de violência física, como o último golpe, após o clérigo perceber que não havia ratos e que era Lázaro quem pegava pedaços de pão para comer escondido.

No Quarto Tratado, por sua vez, há uma severa crítica quanto ao desrespeito dos eclesiásticos ao voto de castidade. O "fraile de La Merced", que frequentemente visitava prostitutas, abusa sexualmente de Lázaro, fato que embora não seja dito explicitamente, evidencia e, sobretudo, denuncia a imoralidade e hipocrisia de alguns cristãos. O "buldero", no Quinto Tratado, enganava ao povo e vendia indulgências, contradizendo, assim, o comportamento esperado de um cristão. Lázaro o descreve como: "El más desenvuelto y desvergonzado echador dellas que yo jamás vi ni ver espero ni pienso que nadie vio, porque tenía y buscaba modos y maneras y muy sutiles invenciones."

Nota-se claramente a crítica à busca pelo lucro por parte da Igreja, além do abusivo desprezo desta pela fé das pessoas. Lázaro, nesse sentido, ainda diz: "¡Cuántas de estas deben hacer estos burladores entre la inocente gente!"

Por fim, no Sétimo Tratado, o "arcipreste" aparece como figura de corrupção, hipocrisia e de desrespeito à castidade. O eclesiástico arma o casamento de Lázaro com sua criada, mas na intenção de encobrir a sua relação com ela, como uma espécie de suborno. Segundo Kadyan (2014), Lázaro percebe a atitude do "arcipreste" e, apesar dos avisos, prefere ignorá-los a seu próprio favor, portando-se, assim, como um típico pícaro.

\section{Considerações FinaIs}

No período de transição da Idade Média para o efervescente contexto renascentista, inaugura-se uma nova concepção de vida na qual o homem é o centro do mundo; perspectiva fortemente presente em La Celestina através da inovação em seu fundo filosófico e moralizante acerca das causas humanas. Assim, a obra pode ser considerada um marco na transformação do pensamento espanhol e, consequentemente, de sua literatura, vista a constante consciência de crise diante do contexto da Idade Média.

Embora tema de grande debate na literatura, a questão religiosa em La Celestina se dá através de uma sátira cuja crítica tem o poder de alcançar tudo. A crítica religiosa presente na 
obra não só destrói os valores judaico-cristãos, como perverte os aspectos sacros, na mesma medida em que inverte e questiona os valores sociais e poéticos vigentes.

O conteúdo herético presente em Lazarillo de Tormes retrata de forma crítica a sociedade da época e o sistema social e clerical vigente, cujo poder condiciona e determina toda a estrutura da vida em sociedade.

Nesse sentido, o pícaro de nome bíblico, Lázaro, encarna, segundo Shekhar, um processo educativo inverso, no qual através dele, se pode observar um severo retrato de uma Igreja (a qual tem como figuras emblemáticas as personagens aqui mencionadas) hipócrita e corrupta, composta por eclesiásticos que buscam beneficiar-se através dela. Lázaro, entretanto, enquanto pícaro, procura sobreviver apesar de perceber e tomar consciência dos abusos e contradições por partes dos cristãos e da própria igreja enquanto instituição, cujo poder exerce influência em toda a sociedade. 
Notas

1 MARAVALL, José Antonio: El mundo social de "La Celestina'; Madrid, Gredos, 1964.

2 Navarroadvoga a hipótese de que Lazarillo de Tormes seja de autoria de Alfonso de Valdés (Cf. NAVARRO, Rosa. "Suplico a vuestra merced..." Invitación a la lectura del Larillo de Tormes. Editorial Academia del Hispanismo, 2008).

3 Sem data. 
ANÓNIMO. Lazarillo de Tormes. EspasaCalpe, Madrid, 1972.

BORREGO, Esther. Fernando de Rojas y la Celestina: una obra entre la Edad Media y los Siglos de Oro, 2014. Disponível em: $<$ http://www.bne.es/es/Actividades/Ciclos/ Temporales/2014/Cicloclasicos/Sesion2.html $>$.

JIMÉNEZ, Inés Barba. Relaciones sociales en La Celestina: nobles contra criados, mujeres contra hombres. Publicaciones Didácticas, $\mathrm{N}^{\circ}$ 64, 2015.

KADYAN, Karishma. La probibición del "Lazarillo de Tormes" durante la inquisición española: el anticlericalismo, 2014.

MARTÍN, Maria Jesús. El Aspecto Religioso en La Celestina. Verba hispánica, VIII, 1999.

MORANTA, Inmaculada Rodríguez. La sátira erasmiana en el Diálogo de Mercurio y Carón de Alfonso de Valdés, 2012. Disponível em: $<$ http://parnaseo.uv.es/Lemir/Revista/Revis ta16/08 Rodriguez Inma.pdf $>$.

NAVARRO, Rosa. "Suplico a vuestra merced..." Invitación a la lectura del Larillo de Tormes. Editorial Academia del Hispanismo, 2008.

RAMOS, Teresa Cecília de Oliveira. Alguns aspectos da religiosidade em La Celestina, de Fernando de Rojas. 2. Congr. Bras. Hispanistas, 2002.

Disponível em: $<$ http://www.proceedings.scielo.br/scielo. php?pid=MSC0000000012002000200045\&sc ript $=$ sci arttext $>$.

ROJAS, Fernando. La Celestina. Versão digital. precursor de la novela picaresca y retrato crítico de la sociedad de siglo XVI.S/D.

VALDÉS, Alfonso de. Diálogo de Mercurio y Carón. Cátedra: Letras Hispánicas. S/D.

VILLANUEVA, Francisco Márquez. Crítica Social e Crítica Religiosa en el Lazarillo: la denuncia de un mundo sin caridad, 1968. In: RICO, F. Historia y Crítica de la Literatura Española, Barcelona, Ed. Crítica, 1980.

SHEKHAR, Anshu. Lazarillo de Tormes: 